\title{
Why Youths Choose to Become Volunteers: From the Perspective of Belief
}

\author{
By Jasmin Arif Shah* \\ Turiman Suandi $i^{\dagger}$ \\ Siti Raba'ah Hamzah \\ Ismi Arif Ismail ${ }^{+}$
}

\begin{abstract}
The purpose of the paper is to examine the engagement of youth in volunteerism and looks at the belief factor underlying youth participation in volunteering activities. Data were collected from the respondents using personally administered questionnaires. A survey was carried out from May to September 2013 involving 342 randomly selected respondents. The respondents ages between $15-$ 40 years $(M$ age $=24.8, S D=4.7)$. The results indicated $69.9 \%$ $(M=2.6930, \quad S D=.47446)$ of the respondents attributed their participation in volunteerism to the belief factor. The level of belief in volunteering was high among youths. However, it should be noted that the factor may vary according to the needs of each individual. Only $0.6 \%$ of the youths had low belief in volunteering activities. The findings of the present study might be useful to volunteer organizations in helping them design interventions to boost volunteerism.
\end{abstract}

\section{Introduction}

Volunteering activities in Malaysia are on the rise. A recent study showed that over $74.6 \%$ (5019) of a sampling of Malaysian youths indicated that they were involved with volunteering activities and programs (Turiman et al., 2011). The history of volunteerism in Malaysia did not differ much from that of other societies (Siti Hawa, 2002). It began with individuals' commitment to religious as well as charitable altruism, as an act in response to human tragedies caused by wars, political conflicts or economic crisis (Siti Hawa, 2002). There is now public interest in volunteerism but more can be done to make it part of our mainstream culture. The majority of people who join volunteer activities are retirees; the younger generation and professionals face constraints such as time if they want to be fully involved in volunteer activities (Siti Hawa, 2002). The government of Malaysia places great emphasis on

\footnotetext{
*Reseacher, Putra Malaysia University, Malaysia.

${ }^{\dagger}$ Lecturer, Putra Malaysia University, Malaysia.

${ }^{\star}$ Youth and Sport Officer, Putra Malaysia University, Malaysia.

${ }^{+}$Lecturer, Putra Malaysia University, Malaysia.
} 
issues of youth development, especially those related to volunteering and social engagement. Development agencies are urged to work together to provide a conducive educational environment for young people to be guided and to learn, as well as to be creative and innovative through constant interaction with the community (Azimi, Turiman \& Ezhar, 2002).

Malaysian government agencies and Non-Government Organizations (NGOs) have put in considerable effort to promote volunteerism. Generally, many Malaysians are aware of and agree with the benefits of being involved in volunteering activities. Nevertheless, there is still a considerable segment of the population that does not participate in volunteering activities (Azizan, 1995). While there are numerous benefits of volunteerism such as helping to promote active learning, provide experience that will strengthen commitment to civic participation, expand educational experience, and improve community service, there are many challenges that volunteers need to overcome (Terry, 2005; Lee et al., 2007; Barbara et al., 2011; Willems et al., 2012; Kauthar et al., 2013).

Volunteers serve as important reservoirs of knowledge for development programs and can help ensure that development-related advocacy campaigns are relevant and legitimate. By participating in volunteering or social activism, or both, people can be empowered with confidence, skills, and knowledge necessary to effect changes in their world (CIVICUS: World Alliance for Citizen Participation, International Association for Volunteer Effort (IAVE) \& United Nation Volunteer, 2008).

Studies have shown that active volunteers are influenced by their beliefs in a cause. They constantly seek out opportunities to volunteer, and they sustain their volunteer activities over extended periods of time. The Malaysian youth community is multicultural and reflects the larger population. It comprises about $57 \%$ Malay, $25 \%$ Chinese, $7 \%$ Indian, and $10.1 \%$ non-citizen and indigenous population (Malaysian Ministry of Youth and Sport). Although previous research has put forward some general propositions about youth involvement in volunteerism, research related to youths' beliefs in volunteerism in Malaysia is still lacking. Hence this study has been undertaken to examine the extent to which beliefs underpin youth engagement in volunteerism. In this study, the focus is on youth volunteers and how their beliefs affect the rate of volunteerism.

\section{Definition of Term}

Volunteering in this study includes any activity which is unpaid, undertaken freely and benefits others or the environment (beyond close family and friends). This broad definition includes both 'formal' volunteering (through a group or organization) and 'informal' volunteering (as an individual). Volunteering can generally be described as the act of giving without expecting anything in return. Volunteering can be categorized in four ways, namely mutual aid or self-help, philanthropy or service to others, civic participation, and advocacy or campaigning (United Nations Volunteer, 2011). 
People often join an organization because it meets their needs. The needs may be for business, friendship, a sense of belonging or for various other selfserving reasons. Studies have shown that people may also lend a helping hand because of empathy.

Whilst there is no one accepted definition of youth, for the purpose of this research we have taken youth as there aged 15 - 40 years as our range of interest in line with the Malaysian National Youth Development Policy (2007).

Conceptually, beliefs closely associated with attitude and behavior. Beliefs are what we know about an object or what we think we know about it. The study detailed out the two subscales, namely normative beliefs and self beliefs in measuring the belief factor. The theory of planned behavior by Ajzen (2002) cites the belief factor as underpinning the constructs of attitude, subjective norm, and perceived behavioral control.

Operationally in this study, the measures of self belief consist of items which include the following statement about self belief were asked as follow: 'I volunteer because I feel that volunteering is a feel-good experience'; 'I volunteer because volunteering makes me feel like a good person'; 'I volunteer because volunteering makes me feel important'; 'I volunteer because volunteering makes me feel useful'; 'I volunteer because volunteering keeps me busy'; 'I volunteer because I feel that volunteering gives me a better understanding of what life is about'; 'Volunteering has had little effect on my self-esteem'; 'I have not changed as a person through volunteering'; 'I volunteer because I feel that volunteering has given me the opportunity to appreciate the differences in people'; and 'I feel more settled in myself after volunteering'.

Next, the normative belief towards engagement in volunteering activities which include the following: 'I have made many friends through volunteering'; 'I volunteer because I look forward to the social events that volunteering affords me'; 'The social opportunities provided by the agency are important to me'; 'I volunteer because I feel that volunteering is a way to build one's social networks; 'I volunteer because volunteering provides a way for me to make new friends'; 'Being appreciated by my volunteer agency is important to me'; I like to work with a volunteer agency, which treats their volunteers and staff alike'; and 'I feel that it is important to receive recognition for my volunteering work.

\section{Literature Review}

\section{Youth and Volunteerism in Malaysia}

Volunteerism can help young people to develop their capacity and skills to become active leaders and citizens. Studies show that young people engaged in volunteering develop positive social behaviors that can help reduce negative risk taking (Siti, 2002; Mardhiyyah et al., 2013; Turiman et al., 2011, Crocetti et al., 2014). Volunteering can also help young people prepare for employment and their transition to responsible adulthood. 


\section{Why Volunteer?}

Volunteerism is a personal investment by people who choose to spend their time and effort to render a service to the community or help the less fortunate without expecting any reward in return. These people are able to make considerable contributions to the society and national development. Volunteerism is related to the helping behavior among people. Volunteering, however, is a specific form of helping behavior, involving a longer-term commitment (Wilson, 2000). Due to its beneficial effect on the society, helping behavior has been the target of much research attention (Oceja et al., 2013). Specifically, volunteering "calls for considerably more planning, sorting out of priorities, and matching of personal capabilities and interests with type of intervention". In other words, "volunteers (a) often seek out opportunities to help others; (b) may deliberate for a considerable amount of time about whether to volunteer, the extent of their involvement, and the degree to which particular activities fit with their own personal needs; and (c) may make a commitment to an on-going helping relationship that may extend over a considerable period of time and that may entail considerable personal costs of time, energy, and opportunity" (Clary et al., 1998).

The question is: why should the focus be on youths?

Research related to youths' beliefs in volunteerism in Malaysia is still lacking. Hence this study has been undertaken to investigate and understand what drives youths to volunteer, from the perspective of their beliefs.

Nurturing the spirit of volunteerism in youth is a major goal of many educational institutions and organizations (Mardhiyyah et al., 2013). There are many factors that motivate people to get involved as volunteers, but most often they simply want to help, to do something important, and/or to assist others in need. Many people engaged in volunteerism feel that they simply must do something to help others.

Other reasons for volunteerism include the desire for exposure to challenging new problems, a chance to demonstrate commitment to an interest in the underserved, a chance to put philosophical convictions into action, a chance to overcome new kinds of obstacles, to encounter interesting new cultures and customs. Volunteers also get the opportunity to learn and acquire new knowledge as well as skills. Hence some people volunteer because they believe that such work is inherently worthwhile, while others feel that volunteering is a good life experience for self and family (Akingbola et al., 2013)

\section{Theory of Planned Behavior}

Many studies on helping behavior have attempted to identify various social and personal factors that affect individual intentions and behavior (Callero, Howard, \& Piliavin, 1987; Marta \& Pozzi, 2007). Influential in this respect has been the application of Fishbein and Ajzen's theory of reasoned action (TRA: Fishbein \& Ajzen, 1975) and its extension, the theory of planned behavior (TPB: Ajzen, 1985). 
The theory of planned behavior cites beliefs as underpinning the constructs of attitude, subjective norm, and perceived behavioral control (Greenslade \& White, 2002). This theory explains that an individual's attitude is a function of salient behavioral beliefs (Ajzen 1988; Fishbein \& Ajzen 1975; Ajzen, 2011). It posits that an individual's behavior is driven by behavioral intentions where behavioural intentions are a function of his or her attitude toward the behavior and subjective norms surrounding the performance of the behavior (Ajzen \& Fishbein, 1980, Ajzen 2002; 2011). This theory suggests that a person's behavior is determined by his or her intention to perform the behavior and that this intention is, in turn, a function of his or her attitude toward the behavior and his or her subjective norm. The best predictor of behavior is intention. Intention is the cognitive representation of a person's readiness to perform a given behavior, and it is considered to be the immediate antecedent of behavior (Ajzen \& Fishbein, 1980; Ajzen 2002; 2011).

Subjective norms are proposed to be a function of normative beliefs, or social pressures from important others (Ajzen 1988; 2002; 2011; Fishbein \& Ajzen 1975). Perceived behavioral control is proposed to be a function of control beliefs, or beliefs concerning whether resources and opportunities are available to perform the behavior. An analysis of these beliefs allows an understanding of the differences between those who perform and those who do not perform the behavior (Warburton et al., 2001; Padgett et al., 2012). As such, the present study will analyse youths' beliefs to provide an understanding of the differences between those individuals who volunteer at a rate above the national average and those who do not. It provides a systematic and comprehensive framework which allows the assessment of personal, social, and psychological effects on volunteering intention.

\section{Influence of the Belief Factor on Engagement in Voluntary Activities}

The level of belief is a strong indicator of the level of commitment. People are often motivated to volunteer because of their passion with a certain cause, even knowing that it might cost them a great deal of personal sacrifice and pain.

Studies have shown that volunteers' beliefs have an impact on their participation in volunteering activities. Psychologists such as Clary, Snyder, Ridge, Copeland, Stukas, Haugen and Miene (1998) found that beliefs are factor intermediaries / mediators on the personality and actions of an individual. A common and widespread opinion is that while self-interest is the primary motivation force behind many human endeavors, self-interest is not necessarily inconsistent with altruistic behavior, and indeed volunteering has been shown to be related to motives that refer to self-interest as well as otherrelated concerns (Clary \& Snyder, 1999; Cornelis et al., 2013). Individual participation in voluntary activities is also determined based on the attitudes of others, an understanding of the needs of the volunteers, and the ability to interact socially.

The propensity to participate in voluntary activities is also influenced by the selection of volunteers, especially the form of services and needs of the 
voluntary program. According to Marta and Pozzi (2008), a high level of belief among volunteers determines their motivation to engage in voluntary activities. This can be explained by the theory of reasoned action of Fishbein and Ajzen (2002) which describes the change in attitudes and behavior in relation to two distinct parts which are subjective norms and social norms. Behavior is determined by specific conduct based on a self belief, without being influenced by the general attitude. It is not only influenced by attitude but by subjective norms. In volunteering activities, propensity, interests, intentions, and loyalty are important factors to strengthen the beliefs of volunteers to continuously participate in the activities and voluntary programs. Further, the willingness to donate and contribute money and time to voluntary organizations is also a belief factor that is embedded in volunteerism through the process of socialization.

The study by Marta and Pozzi (2008) also showed that a high level of belief in volunteering activities can encourage friends and family to participate in similar activities. Parental involvement will also encourage children's involvement in volunteering programs. Similarly, family members such as siblings, brothers and sisters will be influenced to join in volunteering activities if any member of their family is a volunteer. A positive attitude as shown by an altruistic volunteer who gives priority to the happiness and welfare of others is likely to be emulated by members of the close family.

\section{Beliefs and Volunteering}

Volunteering is an important expression of citizenship and fundamental to democracy. It is the commitment of one's time and energy for the benefit of society and the community, and it can take many forms. It is freely undertaken and it is not for financial gain. The principle of non-payment of volunteers is central to this Code and to the wider sector and society's understanding of volunteering (Volunteering: Compact Code of Good Practice, 2003).

While some young people may find it difficult to distinguish between what they can gain through volunteering and through other interventions, or simply as a result of growing up, others clearly differentiate between their experiences as volunteers.

According to the Theory of Planned Behavior, human behavior is guided by three kinds of considerations, viz. beliefs about the likely consequences of the behavior (behavioral beliefs), beliefs about the normative expectations of others (normative beliefs), and beliefs about the presence of factors that may facilitate or impede performance of the behavior (control beliefs). In their respective aggregates, behavioral beliefs produce a favorable or unfavorable attitude toward the behavior; normative beliefs result in perceived social pressure or subjective norm; and control beliefs lead to perceived behavioral control. When these are combined, however, attitude toward behavior, subjective norm, and perception of behavioral control lead to the formation of a behavioral intention (Azjen, 2002;2011; Law and Shek, 2009).

Beliefs are what we know about an object or what we think we know about it (Raven \& Rubin, 1983). Conceptually, beliefs closely associated with 
attitude and behavior. Although beliefs are not directly evaluative, as in the case of attitudes, they may contribute towards our evaluation of a cause. The association of beliefs with attitudes and behaviors is so strong that we can often infer a person's attitude towards an object, or an issue, if we know what his or her beliefs are.

Among various approaches to understanding beliefs related to volunteerism, the functional approach is the most widely studied (Clary et al., 1998). Different people perceive volunteer services with different underlying functions. Some view such services as a chance to learn while others set out to serve people in need. The beliefs held for an activity can be a motivating factor for engaging in that particular activity. The functional approach conceptualizes each category of beliefs as a discrete function for the person.

Law (2008) developed five types of beliefs about volunteerism among adolescents. These beliefs can be further classified as "other-serving belief" and "self-serving belief": (i) Prosocial value function (other-serving belief) refers to serving other people; (ii) Understanding function (self-serving beliefs) refers to the possibility of learning while in service eg. acquire skills and knowledge; (iii) Socializing function (self-serving belief) refers to the socializing aspect of services either delivering in groups or individuals; (iv) Future plan function (self-serving belief) refers to potential tangible benefits to adolescents; and (v) Well-being function (self-serving belief) is related to psychological well-being.

The focus of this study was on belief factor among youth in relation to participation in volunteerism. It was hypothesised that belief factor (in the areas of normative beliefs and self beliefs) would direct relationship between normative beliefs and self beliefs on youth participation. Accordingly, the following hypotheses were tested:

Hypothesis 1: Participation is positively related to normative beliefs. Hypothesis 2: Participation is positively related to self beliefs.

\section{Purpose and Methodology}

The purpose of this research is to investigate how youths' belief in volunteerism affect the level of participation as volunteers. Studies have shown that beliefs have an impact on volunteers to actively participate in volunteer activities (Fishbein et al., 1975; Greenslade et al., 2002; Law et al., 2009). However, there is scant research on Malaysian youths with regard to their beliefs and volunteering activities at the time of writing. Hence, this study has been undertaken to examine the belief factor contributing to Malaysian youth engagement in volunteerism.

The study detailed out the two subscales, namely normative beliefs and self beliefs in measuring the belief factor. Data were collected from the subjects using personally administered questionnaires. All participants were informed the study was on voluntary basis. Verbal consent was obtained from 
the participants and they were assured that the information given would be confidential. A small token was offered to participants in order to encourage better co-operation. Data collection was conducted during weekdays and weekends. The participants were youths (15 to 40 years of age). To provide an adequate level of confidence in this study, the sample size was 342.

The survey was carried out to measure the belief of Malaysian youth in volunteering activities. Questions were rated in a 10-point Likert-scale format was used, ranging from 1 (strongly disagree) to 10 (strongly agree). While, the scoring level of youth belief were regarded as Low (1.00-4.00), Moderate (5.00-7.00) and High (8.00-10.00).

\section{Results and Discussion}

The demographic profiles analyzed were gender, ethnicity, and race, as shown in Table 1. There were 199 male respondents (58.2\%) while 143 respondents were female $(41.8 \%)$. From the profile information, most of the youths involved in volunteer activities were Malays $(81.3 \%)$. It followed by Chinese $10.5 \%$, Others $5.3 \%$ and Indian $2.9 \%$. The religious background of the respondents was grouped into four categories, namely Muslims, Christians, Buddhists and Hindus. From the survey, it was found that Muslims religious, i.e. 288 youths $(84.2 \%)$ formed the largest category. Those with Buddhists religious comprised $7 \%$ of the respondents, Christians 18\%, and Hindus 3.5\%.

Table 1. Profile of Respondents

\begin{tabular}{|c|c|c|}
\hline Demography & Frequency & Percent (\%) \\
\hline \multicolumn{3}{|c|}{ Gender } \\
\hline Male & 199 & 58.2 \\
\hline Female & 143 & 41.8 \\
\hline \multicolumn{3}{|c|}{ Ethnicity } \\
\hline Malay & 278 & 81.3 \\
\hline Chinese & 36 & 10.5 \\
\hline Indian & 10 & 2.9 \\
\hline Others & 18 & 5.3 \\
\hline \multicolumn{3}{|c|}{ Religious background } \\
\hline Muslims & 288 & 84.2 \\
\hline Christians & 18 & 5.3 \\
\hline Buddhists & 24 & 7.0 \\
\hline Hindus & 12 & 3.5 \\
\hline
\end{tabular}

Volunteerism plays an important role in developing the potential of youth. It is an important way of supporting youths in their diversity, while fostering their inclusion in peace and sustainable human development process. As shown in Table 2 , the level of youth engaged in voluntary activities was high, at $66.7 \%$. $(M=2.6754, S D=.48730)$. 
On examining the hypotheses, $\mathrm{H} 1$ demonstrated a positive relationship between engagement to normative beliefs. Hypothesis 1 was, therefore, supported. The level of normative belief among youth engaging in volunteering activities was also high. The result indicated 69.9\% $(M=2.6930, S D=.47446)$ of youth agreed that their belief in volunteerism helped to encourage their participation in volunteering activities. However, it should be noted that the belief factor varied according to the needs of each individual, e.g. $0.6 \%$ of the youths had low belief in volunteering activities. Meanwhile, hypothesis 2 was supported, engagement is positively related to self beliefs. The level of volunteerism in self belief among the majority of youths $(58.8 \%)$ was at a moderate level $(M=2.3363, S D=.54780)$.

Table 2. Level of Youth Engagement, Normative Belief and Self Belief among youths engaged in Volunteerism

\begin{tabular}{|c|c|c|c|c|}
\hline Level & Frequency & Percent (\%) & Mean & SD \\
\hline \multicolumn{3}{|c|}{ Engagement } & \multirow{4}{*}{2.6754} & \multirow{4}{*}{.48730} \\
\hline Low & 3 & 0.9 & & \\
\hline Moderate & 111 & 32.5 & & \\
\hline High & 228 & 66.7 & & \\
\hline \multicolumn{3}{|c|}{ Normative Belief } & \multirow{4}{*}{2.6930} & \multirow{4}{*}{.47446} \\
\hline Low & 2 & 0.6 & & \\
\hline Moderate & 101 & 29.5 & & \\
\hline High & 239 & 69.9 & & \\
\hline \multicolumn{3}{|c|}{ Self Belief } & \multirow{4}{*}{2.3363} & \multirow{4}{*}{0.54780} \\
\hline Low & 13 & 3.8 & & \\
\hline Moderate & 201 & 58.8 & & \\
\hline High & 128 & 37.4 & & \\
\hline
\end{tabular}

\section{Intercorrelation towards Engagement in Volunteering}

The relationship between engagement and belief, self-belief, was investigated using the Pearson product-moment correlation coefficients. Preliminary analyses were performed to ensure there are no violation of the assumptions of normality and linearity. As depicted in Table 3, they are highest relationship and positive linear relationship was found between engagement and normative belief $(r=.71, p=0.000)$. The relationship between and engagement and self belief $(r=.58, p=0.000)$ indicates a moderate positive linear.

Table 3. Pearson's Correlation Coefficients of Engagement and the Selected Variables

\begin{tabular}{ccccc}
\hline Variables & & $\mathbf{Y}$ & $\mathbf{X}_{\mathbf{1}}$ & $\mathbf{X}_{\mathbf{2}}$ \\
\hline $\mathbf{Y}$ & Engagement & 1.000 & & \\
$\mathbf{X}_{\mathbf{1}}$ & Normative Belief & .708 & 1.000 & \\
$\mathbf{X}_{\mathbf{2}}$ & Self-belief & .581 & .563 & 1.000 \\
\hline
\end{tabular}


According to Law and Shek (2009), beliefs about volunteerism, volunteering intention, volunteering behavior, and purpose in life among volunteers are all inter-related. The beliefs held for an activity can be the motivating factor for engaging in that particular activity. The functional approach conceptualizes each category of beliefs as a discrete function for the volunteer.

Having said that, several issues need to be addressed in encouraging youths to be willing volunteers. There is a need to increase their confidence through peer ambassadors and mentors. We also need to assess influences from various sources (e.g. schools and other educational institutions, families and peers), adapt the length or regularity of their volunteer role to address their transient time commitments, address their access to transport, and understand how young people prefer to communicate in terms of media and styles (Moffatt, 2011).

The functional approach by Clary et al. (1998) is the most extensively studied in relation to the understanding of beliefs associated with volunteering. Using this approach, we can identify people who perceive volunteer service with different underlying functions. Some view volunteer services as an opportunity to learn, while others as a chance to to serve people in need. The findings in this study indicated that youths had a high level of belief in volunteerism. When normative belief is coupled with self belief, it leads to the formation of a behavioral intention to engage in volunteering (Azjen, 2002; 2011; Law and Shek, 2009).

As mentioned earlier, participation in volunteering activities would benefit youth in terms of not only increased skills, but also an enriched educational experience, increased social capital and deeper socio-economic awareness. It would also inculcate a sense of responsibility in giving back to the society.

There are many factors that influence volunteerism among youths. In China, a case study of the 2009 World Games volunteers showed that "participation motivation" was a highly influential factor for youths to participate as volunteers. They did not want to miss out on an event that they could gain a sense of satisfaction from being involved, as well as gaining a broader experience of life, and an opportunity to meet new people and make friends (Law et al., 2009).

The findings of the present study may be of use to volunteer organizations as they can be translated into interventions designed to increase the rate of volunteerism. Campaigns within this domain could focus on changing negative beliefs that individuals might have about participation in volunteerism.

\section{Conclusion and Recommendations}

The findings revealed that level of youth engagement in voluntary activities at the level of normative belief among youth engaging in volunteering activities was high. Thus, it can be concluded that youth belief in 
volunteerism will strongly influence their participation in volunteering activities.

These findings suggest that belief is an important factor which influence a youth's decision to engage in volunteerism. Hence, in forms of practice, it is recommended that a more positive volunteering experiences is exposed to younger volunteers. For those active young volunteers, knowledge regarding important beliefs behind volunteering and the link to behavioral outcomes should be translated into programs that apply these insights. In this study, the belief factor that had been discussed should be taken into account to enhance youth participation and their engagement in volunteerism. It is also important to know the needs and expectations of youth volunteers. It is equally important to have sustainable volunteers. Thus, steps should be taken to engage more youths in volunteerism and to ensure that they become successful volunteers.

Youth voluntary organizations tend to focus their training efforts on the more practical aspects of day-to-day volunteering and the interpretation of leadership in youth development. However, based on our study, guidance and training that focus on how these youth may adapt their work within groups to fit with personally dominant volunteering motives might ensure increased satisfaction. Furthermore, giving guidance to volunteers in interpreting the content of the volunteering experience would be useful to satisfy other motives besides self-oriented beliefs. This would not only boost their passion for engaging in volunteerism, but it would also help them in sustaining their commitment to be as active volunteers.

Theoretically, the study supports most of the theories, specifically the Theory of Planned Behavior by Ajzen \& Fishbein (1980) and Theory of Functional Approach by Clary et al. (1998). These two theories explained that human behavior is guided by the beliefs about the likely consequences of the behavior, the beliefs about the normative expectations of others, and beliefs about the presence of factors that may facilitate or impede performance of the behavior. When these are combined, it will lead to the formation of a behavioral intention.

To summarize, future research on the youth participation in volunteering activities would be served through longitudinal study to lends stronger support to the idea of youth engagement and impact of volunteering upon the young volunteers. The greatest power of longitudinal data is its potential to help us understand change over time at the individual level. Only this type of data can help us to understand the long term impact of youth volunteering on individuals' lives.

\section{Acknowledgements}

It is a pleasure to thank the various people who made this paper possible. Our sincere thanks go to UPM, Serdang, Selangor, Malaysia and Faculty of Educational Studies. We wish to extend our warmest thanks to all those who have helped us with the creation of this paper. Our full gratitude goes to the 
Ministry of Education for enabling this research under the FRGS (Vote number: 5527152) research grants for providing funding to encourage and empower more youth volunteers for the nation.

\section{References}

Ajzen, I., \& Fishbein, M. (1980). Understanding attitudes and predicting social behavior. Englewood Cliffs, NJ: Prentice-Hall.

Ajzen, I. (1985). From intentions to actions: A theory of planned behavior. In J. Kuhl \& J. Beckmann (Eds.), Action control: From cognition to behavior (11-39). Heidelberg: Springer.

Ajzen, I. (1988). Attitudes, personality, and behavior. Chicago: Dorsey.

Ajzen, I. (2002). Perceived behavioral control, self-efficacy, locus of control, and the theory of planner behavior. J. Appl. Soc. Psychol. 32(4), 665-683.

Ajzen, I. (2011). The theory of planned behavior: Reactions and reflections. Psychology \& Health, 26 (9), 1113-1127

Akingbola, K., Duguid, F., \& Viveros, M. (2013). Learning and Knowledge Transfer in Volunteering. In Volunteer Work, Informal Learning and Social Action (pp. 63-78). SensePublishers.

Azimi, H., S. Turiman and T. Ezhar. (2002). Youth organization in Malaysia: Development and potential enhancement. Universiti Putra Malaysia: Serdang.

Azizan Bahari. (1995). Pergerakan Belia: Persoalan dan cabaran. Kuala Lumpur: Institut Kajian Dasar

Barbara AJ, Kirton J, Birakurataki J, Merriman A. (2011). A bridge to the hospice: the impact of a community volunteer programme in Uganda. Palliat Med, 25, 706.

Callero, Peter L., Judy A. Howard, and Jane Allyn Piliavin. (1987). "Helping Behavior as Role Behavior: Disclosing Social Structure and History in the Analysis of Prosocial Action.” Social Psychology Quarterly 50:247-256.

Civicus: World Alliance for Citizen Participation, International Association for Volunteer Effort (IAVE) \& United Nation Volunteer. Volunteering And Social Activism: Pathways for participation in human development. (2008).

Clary, E. G., Snyder, M., Ridge, R. D., Copeland, J., Stukas, A. A., Haugen, J., \& Miene, P. (1998). Understanding and assessing the motivations of volunteers: A functional approach. Journal of Personality and Social Psychology, 74(6), $1516-1530$

Clary, E. G., \& Snyder, M. (1999). The Motivations to Volunteer Theoretical and Practical Considerations. Current directions in psychological science, 8(5), 156159.

Crocetti, E., Erentaitè, R., \& Žukauskienè, R. (2014). Identity Styles, Positive Youth Development, and Civic Engagement in Adolescence. Journal of youth and adolescence, 1-11.

Cornelis, I., Van Hiel, A., \& De Cremer, D. (2013). Volunteer work in youth organizations: predicting distinct aspects of volunteering behavior from self-and other-oriented motives. Journal of Applied Social Psychology, 43(2), 456-466.

Fishbein, M., \& Ajzen, I. (1975). Belief, attitude, intention, and behavior: An introduction to theory and research. Reading, MA: Addison-Wesley.

Greenslade, JH, \& White, KM. (2002). Beliefs underlying above average participation in volunteerism. Australian Journal on Volunteering, 7, 29-35. 
Imam, Syed, Nurullah, Abu, Makol-Abdul, Pute, Rahman, Saodah and Noon, Hazizan. (2009). Spiritual and Psychological Health of Malaysian Youths', Research in the Social Scientific Study of Religion 20: 85-101.

Kauthar Mohamad Kamaludin, Mazanah Muhammad, Nor Wahiza Abdul Wahat, Rahimah Ibrahim. (2013). Challenges in volunteering from cancer care volunteers perspectives. Asian Pac J Cancer Prev, 14, 8, 4795-4800. doi:http://dx.doi.org/ 10.7314/ APJCP. 2013.14.8.4795.

Law, M.F.B. (2008). Volunteer Service Participation among Secondary School Students in Hong Kong. Dissertation Abstracts International, 69(08A). (UMI No. 3326201).

Law, B.M.F. and Shek, D.T.L. (2009). Beliefs about volunteerism, volunteering intention, volunteering behavior, and purpose in life among Chinese adolescents in Hong Kong. The Scientific World JOURNAL: TSW Child Health \& Human Development 9, 855-856. DOI 10.1100/tsw.2009.32.

Lee S, Saito T, Takahashi M, Kai I. (2007).Volunteer participation among older adults in Japan: An analysis of the determinants of participation and reasons for nonparticipation. Archives of Gerontol and Geriatrics, 47, 173-87

Mardhiyyah Sahri, Khairudin Murad, Asmidar Alias, \& Mohd Dasuqkhi Mohd Sirajuddin. (2013). Empowering Youth Volunteerism: The Importance and Global Motivating Factors. Journal of Educational and Social Research MCSER Publishing, Rome-Italy. 3 (7). Doi:10.5901/jesr.2013.v3n7p502

Marta, E. \& Pozzi, M. (2008). Young people and volunteerism: A model of sustained volunteerism during the transition to adulthood. Journal of Adult Development, 15(1), 35-46. DOI 10.1007/s10804-007-9033-4

Ministry of Youth and Sport. http://www.kbs.gov.my

Moffatt, L. (2011). Engaging young people in volunteering: what works in Tasmania? Volunteering Tasmania. Hobart: VT.

Oceja, L., \& Salgado, S. (2013). Why do we help? World change orientation as an antecedent of prosocial action. European Journal of Social Psychology,43(2), 127-136.

Padgett, R. D., Johnson, M. P., \& Pascarella, E. T. (2012). First-generation undergraduate students and the impacts of the first year of college: Additional evidence. Journal of College Student Development, 53(2), 243-266.

Raven, B. H. \& Rubin, J. Z. (1983). Social Psychology. New York: John Wiley \& Sons.

Siti Hawa Ali. (2002). Volunteerism and the Development of Malaysian Social Care System. School of Health Science, University Science Malaysia.

Terry BD (2005). Measuring the Net Benefits of Extension Volunteer Programs. The J Volunteer Administration, 23.

Turiman Suandi, Siti Raba'ah Hamzah, Wan Mahzom Ahmad Shah, Mohd Rezal Hamzah, Azizan Bahari, Ismail Ali, Wan Ibrahim Wan Ismail, Mohd Hafizi Ismail. Determinants of student volunteering in Malaysian Public Universities. International Conference on Youth Development 2011, Palm Garden, Putrajaya. 1st-3rd November 2011.

Volunteering: Compact Code of Good Practice. (2003). http://www.compactvoice. org.uk

Warburton, J., Terry, D. J., Rosenman, L. S., and Shapiro, M. (2001). "Differences between older volunteers and nonvolunteers: attitudinal, normative, and control beliefs," Research on Aging, 23(5), (586-605). 
Vol. 2, No. 1 Shah et al.: Why Youths Choose to Become Volunteers...

Willems J, Huybrechts G, Jegers M, Vantilborgh T, et al (2012). Volunteer decision (not) to leave: Reason to quit versus functional motives to stay. Human Relations, $65,883-900$

Wilson, J. 2000. Volunteering. Annual Review of Sociology, 26, 215-240. 